\title{
Influence of electrodes' distance upon properties of intrinsic and doped amorphous silicon films for heterojunction solar cells
}

\author{
Nils Brinkmann*, Angelika Gorgulla, Anja Bauer, Daniel Skorka, Gabriel Micard, Giso Hahn, \\ and Barbara Terheiden
}

Department of Physics, University of Konstanz, P.O. Box PV 676, 78457 Konstanz, Germany

Keywords amorphous silicon, heterojunctions, solar cells, surface passivation

*Corresponding author: e-mail nils.brinkmann@uni-konstanz.de, Phone: +49 7531 882088, Fax: +49 7531883895

In this work, the influence of electrodes' distance upon the properties of amorphous silicon (a-Si:H) deposited by plasmaenhanced chemical vapor deposition method on both intrinsic and doped a-Si:H films is investigated in terms of their electrical, optical, and structural characteristics. For this purpose, Fouriertransform infra-red and secondary-ion mass-spectroscopy as well as photoconductance decay, spectral ellipsometry, and conductivity measurements are employed. Electrodes' distance is varied from 20 to $120 \mathrm{~mm}$. Regarding the passivation quality of the a-Si:
H film an optimum electrodes' distance of $60 \mathrm{~mm}$ is found. In addition, electrodes' distance is detected to have a great influence on the accelerated initial growth rate, which strongly diminishes with increasing distance. Thus, electrodes' distance also determines the overall thickness of thin intrinsic a-Si:H films being particularly interesting for utilization in heterojunction solar cells. With doped a-Si:H films, however, electrodes' distance influences mainly the dopant concentration in the films and therewith their conductivity.
1 Motivation Recently the silicon heterojunction solar cell concept, which utilizes stacked films composed of an intrinsic amorphous silicon (a-Si:H) passivation and a doped a-Si:H emitter layer featuring a high band gap in comparison to crystalline silicon (c-Si), has attracted much attention [1]. Its key advantages are the high conversion efficiency potential (24.7\%) [2] and the fact that the whole solar cell production process can be carried out at economical and energy efficient temperatures below $200{ }^{\circ} \mathrm{C}$ [3]. In order to attain very high open-circuit voltages $\left(V_{\mathrm{oc}}>720 \mathrm{mV}\right)$, and therewith high efficiencies, it is inevitable to insert an effective passivating film of intrinsic a-Si:H between the crystalline silicon (c-Si) base and the doped a-Si:H emitter layer [1]. This buffer layer requires to be thin $(\leq 6 \mathrm{~nm})$ in order not to reduce the fill factor of the solar cell due to transport losses within this layer [4]. Numerous investigations concerning the properties, in particular the passivation quality of intrinsic (i) a-Si:H films have been carried out so far (e.g., [5-7]), but only little has been published on the influence of the electrodes' distance of the commonly used plasma-enhanced chemical vapor deposition (PECVD) setup (operating in parallel-plate mode) upon the properties of intrinsic a-Si:H [8-12]. These publications focus mainly on the growth rate, the hydrogen content and the nano-crystallinity of the intrinsic a-Si:H films. None of them examines the influence on the passivation quality or the accelerated initial growth rate of the (i)a-Si:H films. Furthermore, only small electrodes' distances ranging from 4 to $50 \mathrm{~mm}$ are investigated in these studies.

Regarding the utilization of doped amorphous Si layers in silicon heterojunction solar cells, an optimal doping concentration in this layer in respect of solar cell efficiency has been found being a compromise between the risen defect density and a higher doping concentration. The latter being necessary to establish a high band bending [13], and a good contact with the transparent conductive oxide (TCO) layer [14]. To our knowledge, however, no study is published on the influence of electrodes' distance upon the properties of doped a-Si:H films so far.

Therefore, this work examines the influence of electrodes' distance upon the electrical, optical, and structural properties of PECV-deposited thin amorphous silicon films with the overall aim to make such layers employable for silicon heterojunction solar cells. Electrodes' distance is 
varied over the wide range from 20 up to $120 \mathrm{~mm}$. Both, intrinsic and doped a-Si:H films are examined.

2 Experimental details The a-Si:H layers are produced using a commercial PECVD reactor (PlasmaLab 100 from Oxford Instruments) in a parallel plate configuration operating at a radio frequency (RF) of $13.56 \mathrm{MHz}$. The decomposition of silane $\left(\mathrm{SiH}_{4}\right)$ generates the desired a-Si:H films. In some cases, the precursor gas is diluted with a hydrogen $\left(\mathrm{H}_{2}\right)$ dilution of $R_{\mathrm{H}_{2}}=\left[\mathrm{H}_{2}\right] /\left(\left[\mathrm{H}_{2}\right]+\left[\mathrm{SiH}_{4}\right]\right)$. In order to grow the p-doped a-Si:H films, diborane $\left(\mathrm{B}_{2} \mathrm{H}_{6}\right)$ is added to the precursor gases with a dilution ratio of $R_{\mathrm{B}_{2} \mathrm{H}_{6}}=\left[\mathrm{B}_{2} \mathrm{H}_{6}\right] /\left(\left[\mathrm{B}_{2} \mathrm{H}_{6}\right]+\left[\mathrm{SiH}_{4}\right]\right)$. Deposition temperature $\left(225^{\circ} \mathrm{C}\right), \mathrm{SiH}_{4}$ flow, and pressure are kept constant for all layers. Deposition power is changed only for the experiment in Section 4.3 but kept constant at $50 \mathrm{~W}$ otherwise.

The passivation quality of the a-Si:H films is evaluated by means of the effective minority charge carrier lifetime $\tau_{\text {eff }}$ of a-Si:H passivated boron-doped float-zone (FZ) silicon wafers. Those are $250 \mu \mathrm{m}$ thick with a specific resistivity of $2 \Omega \mathrm{cm}$ and (100)-oriented. The samples are firstly cut by laser to $5 \times 5 \mathrm{~cm}^{2}$ pieces and subsequently etched in a chemical polishing solution in order to remove the laser damage [15]. Secondly, the wafers are subjected to a standard RCA cleaning [16]. The RCA oxide is stripped off in diluted hydrofluoric acid (HF, 2\%) shortly before the deposition of the a-Si:H films. For symmetrical lifetime samples, identical a-Si:H films are deposited on both sides of the wafer. The deposition is followed by an annealing step in ambient air $(2 \mathrm{~min}$ at $300{ }^{\circ} \mathrm{C}$ ) exploiting the full passivation potential. $\tau_{\text {eff }}$ is determined as a function of excess carrier density by means of photoconductance decay (PCD) measurements (WCT-120 Lifetime Tester from Sinton Consulting, Inc.) [17]. Based on these measurements, the a-Si:H/c-Si interface defect density $N_{\mathrm{s}}$ and the interface charge density $Q_{\mathrm{s}}$ are calculated utilizing the Olibet model [18]. Using $\tau_{\text {eff }}$ evaluated at an excess carrier density of $\Delta n=1 \times 10^{15} \mathrm{~cm}^{-3}$ the surface recombination velocity $\left(S_{\text {eff }}\right)$ is calculated according to (assuming identical $S_{\text {eff }}$ on both sides of the wafer) [19]

$$
S_{\text {eff }}=\frac{W}{2}\left(\frac{1}{\tau_{\text {eff }}}-\frac{1}{\tau_{\text {bulk }}}\right)
$$

with $\tau_{\text {bulk }}$ being carrier lifetime in the silicon bulk, and $W$ denoting wafer thickness. For the calculation of $S_{\text {eff }}$ infinite bulk lifetime $\tau_{\text {bulk }}$ is assumed for the float-zone wafers used yielding an upper limit of $S_{\text {eff }}$.

The thickness of the deposited a-Si:H films $d_{\text {film }}$ as well as other characteristics such as refractive index $n$ and extinction coefficient $k$ are ascertained by measuring ellipsometric spectra $(\psi, \Delta)$ between 250 and $1000 \mathrm{~nm}$. These data are fitted by a Kramers-Kronig-consistent model to extract the quantities to be determined [20]. Layer thickness is partly cross-checked via high-resolution transmission electron microscopy confirming the ellipsom- etry findings. The optical band gap $E_{\text {gap }}$ is calculated from the ellipsometric data by using Tauc's formula [21]

$$
\alpha(\hbar \omega) \propto \frac{\left(\hbar \omega-E_{\text {gap }}\right)^{2}}{\hbar \omega}
$$

with the absorption coefficient $\alpha$ and the energy of the incoming light $\hbar \omega$.

For conductivity measurements the doped a-Si:H films $\left(d_{\text {film }}>100 \mathrm{~nm}\right)$ are deposited on borosilicate glass. Afterwards, two coplanar titanium/palladium/silver contacts are applied on top of the doped a-Si:H films by means of an electron beam evaporator. The contacts are rectangular ( $8 \mathrm{~mm}$ long and $2 \mathrm{~mm}$ wide). The distance between the two contacts amounts to $2 \mathrm{~mm}$. The samples are subsequently sintered for $90 \mathrm{~min}$ at $150{ }^{\circ} \mathrm{C}$ in a nitrogen atmosphere in order to establish an ohmic contact between metal and the doped a-Si:H films. Thereupon, lateral conductivity in the dark $\sigma_{\text {dark }}$ is ascertained by IV-characteristic measurements of the manufactured samples using a Keithley 617 electrometer in a two point configuration. Contact resistance $R_{\mathrm{c}}$ between the a-Si:H film and the contacts has been neglected, since $R_{\mathrm{c}}$ is orders of magnitude smaller than the resistance contribution of the a-Si:H films.

A qualitative bonding analysis of the a-Si:H films is performed by means of Fourier-transform infrared spectroscopy (FTIR). For this purpose, the a-Si:H film is deposited on only one side of the silicon substrate $\left(d_{\text {film }}>150 \mathrm{~nm}\right)$. The other side is mechanically polished. The FTIR measurements are performed at room temperature in nitrogen atmosphere with a wave number resolution of $7 \mathrm{~cm}^{-1}$. The effective absorption coefficient $\alpha_{\text {eff }}$ is calculated according to [22]

$$
\alpha_{\text {eff }}=\frac{A_{\text {film }}}{d_{\text {film }} \times \log _{10} \mathrm{e}}
$$

with $A_{\text {film }}$ being the absorbance of the a-Si:H films $\left(A_{\text {film }}=A_{\text {sample }}-A_{\text {substrate }}\right)$. A baseline correction, i.e., a subtraction of the Drude term, is applied to all FTIR data prior to the calculation of $\alpha_{\text {eff }}$.

Integrating over the absorption band of interest yields the intensity $I$ of this bond [23]

$$
I=\int \frac{\alpha_{\text {eff }}(\omega)}{\omega} \mathrm{d} \omega .
$$

The method established by Langford et al. [23] is then employed to calculate the $\mathrm{Si}-\mathrm{H}\left(2000 \mathrm{~cm}^{-1}\right)$ and $\mathrm{Si}-\mathrm{H}_{2}$ $\left(2090 \mathrm{~cm}^{-1}\right)$ bond densities.

The absolute concentration of boron atoms within the amorphous network of the a-Si:H films $\left[C_{\mathrm{B}}\right]_{\text {film }}$ is measured by means of secondary-ion mass-spectroscopy (SIMS) [24]. Dividing $\left[C_{\mathrm{B}}\right]_{\text {film }}$ by the molecular dopant concentration in the plasma $\left[C_{\mathrm{B}}\right]_{\text {gas }}$ yields the impurity distribution coefficient $d_{\mathrm{I}}[25,26]$, with $\left[C_{\mathrm{B}}\right]_{\mathrm{gas}}=2 \times\left[\mathrm{B}_{2} \mathrm{H}_{6}\right] /\left[\mathrm{SiH}_{4}\right]$. 


\section{Intrinsic a-Si:H films}

3.1 Initial growth rate and steady-state growth rate The density of unconsumed precursor gas molecules is at the very beginning of plasma ignition higher than the consumed molecule density compared to the steadily burning plasma where a balance of consumed and unconsumed molecules occurs. As a natural consequence, the initial growth rate is higher than the constant growth rate of the burning plasma [27]. The latter is subsequently named steady-state growth rate. By linear fitting of the film thickness readings in dependence on the deposition time of several identical processed samples, the steady-state growth rate can be determined (slope of the line of best fit, cf. Fig. 1). Since it is not possible to assess the duration of plasma ignition without further ado, the accelerated initial growth is characterized in terms of thickness (nm) rather than in terms of rate $\left(\mathrm{nm} \mathrm{s}^{-1}\right)$. The asymptotic thickness of this fast grown layer, as it is subsequently named, corresponds to the $y$-axis intercept of the line of best fit to a-Si:H film thickness dependent on deposition time (Fig. 1).

Steady-state growth rate of the a-Si:H films remains almost constant $\left(0.3 \mathrm{~nm} \mathrm{~s}^{-1}\right)$ for electrodes' distances larger than $40 \mathrm{~mm}$ but ascends for smaller electrodes' distances up to $0.48 \mathrm{~nm} \mathrm{~s}^{-1}$ (Fig. 2).

Fast grown layer thickness diminishes from $17.7 \mathrm{~nm}$ at an electrodes' distance of $20 \mathrm{~mm}$ to $3.5 \mathrm{~nm}$ at $120 \mathrm{~mm}$ (Fig. 2). It ought to be noted, that the overall thickness of the intrinsic buffer layer has to be less than $6 \mathrm{~nm}$ to be utilizable in heterojunction solar cells [1, 4]. However, by adding hydrogen to the precursor gas, fast grown layer thickness can be reduced down to $2.6 \mathrm{~nm}$ at an electrodes' distance of $60 \mathrm{~mm}$ without the occurrence of epitaxial growth at the interface (Fig. 3). Thereby, the steady-state growth rate decreases from $0.31 \mathrm{~nm} \mathrm{~s}^{-1}\left(R_{\mathrm{H}_{2}}=0 \%\right)$ to $0.24 \mathrm{~nm} \mathrm{~s}^{-1}$ $\left(R_{\mathrm{H}_{2}}=80 \%\right)$ due to the etching off of weak bonds by hydrogen [28].

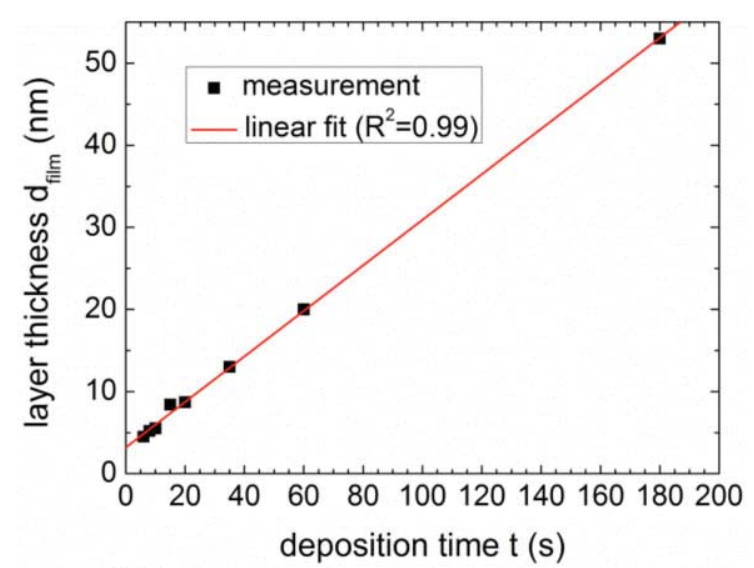

Figure 1 Determination of the fast grown layer thickness ( $y$-axis intercept) and steady-state growth rate (slope). Samples are deposited at an electrodes' distance of $60 \mathrm{~mm}$ using a hydrogen dilution of $80 \%$.

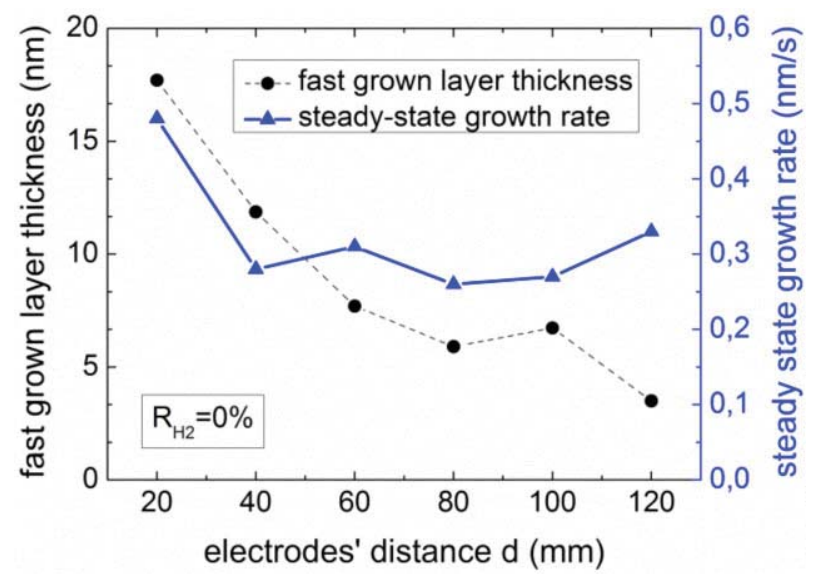

Figure 2 Fast grown layer thickness (circles) and growth rate (triangles) of deposited a-Si:H films dependent on electrodes' distance. Lines are guide to the eyes only.

3.2 Passivation quality The deposition of the a-Si:H films is carried out by varying the electrodes' distance (20$120 \mathrm{~mm}$ ) only (pressure and power are kept constant) and without adding hydrogen to the precursor gas. Additionally, at an electrodes' distance of $60 \mathrm{~mm}$, the a-Si:H layers are deposited with different hydrogen dilutions $R_{\mathrm{H}_{2}}$ (Fig. 3).

Independent of the electrodes' distance, all c-Si FZ wafers passivated by a-Si:H films $\left(d_{\text {film }} \sim 20 \mathrm{~nm}\right)$ need to be annealed on a hot plate in ambient air $\left(300^{\circ} \mathrm{C}, 2 \mathrm{~min}\right)$ to exploit the full passivation potential. Resulting minority charge carrier lifetime and interface defect density as a function of electrodes' distance are depicted in Fig. 4. A maximum $\tau_{\text {eff }}$ of $2.6 \mathrm{~ms}\left(S_{\text {eff,max }}=4.6 \mathrm{~cm} \mathrm{~s}^{-1}\right)$ is reached at an electrodes' distance of $60 \mathrm{~mm}$. With smaller and larger electrodes' distances, lifetime drops sharply to less than $0.3 \mathrm{~ms}$ at an electrodes' distance of $20 \mathrm{~mm}$. This drop in

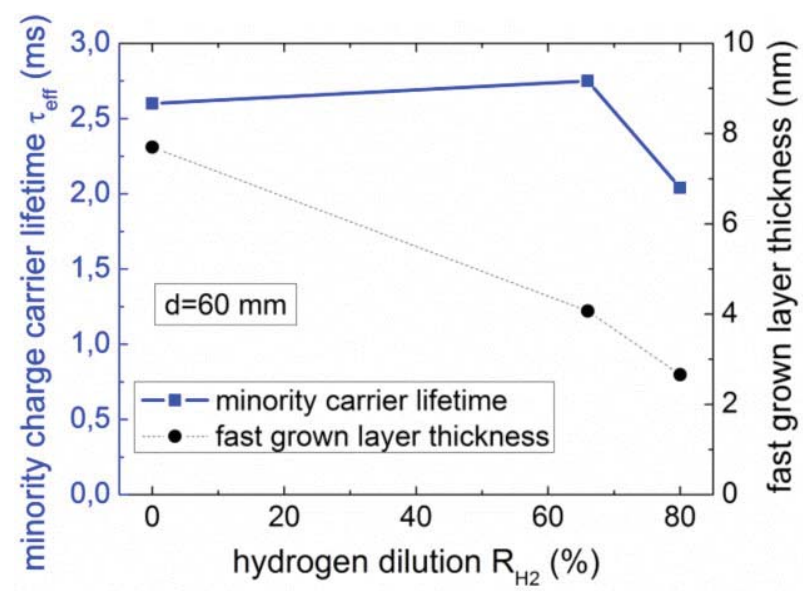

Figure 3 Minority charge carrier lifetime (squares) and fast grown layer thickness (circles) of deposited a-Si:H films dependent on silane to hydrogen gas flow $R_{\mathrm{H}_{2}}$ deposited at a constant electrodes' distance $d$ of $60 \mathrm{~mm}$. Lines are guide to the eyes only. 


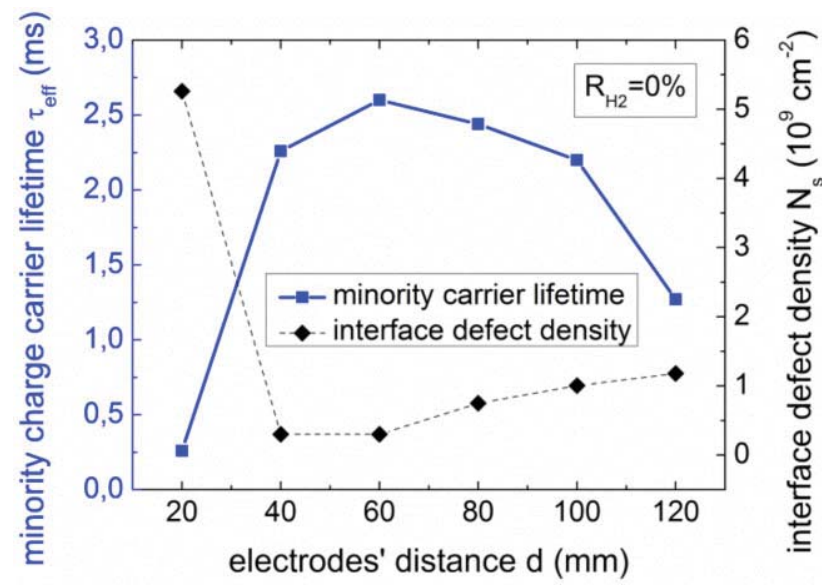

Figure 4 Minority charge carrier lifetime (squares) and interface defect density $N_{\mathrm{s}}$ (diamonds) of deposited a-Si:H films dependent on electrodes' distance. Lines are guide to the eyes only.

lifetime is accompanied by a steep rise of $N_{\mathrm{s}}$, which naturally depends on the trend of minority charge carrier lifetime for all electrodes' distances (Fig. 4).

3.3 Bonding structure The bonding structure of the a-Si:H films is investigated by means of FTIR spectroscopy. The ascertained bonding densities of the $\mathrm{Si}-\mathrm{H}$ bond $\left(2000 \mathrm{~cm}^{-1}\right)$ and the $\mathrm{Si}-\mathrm{H}_{2}$ bond $\left(2100 \mathrm{~cm}^{-1}\right)$ are depicted in Fig. 5. Whereas $\mathrm{Si}-\mathrm{H}_{2}$ bonding density stays almost constant with electrodes' distance, except for large electrodes' distances, the $\mathrm{Si}-\mathrm{H}$ bonding density follows the trend of minority charge carrier lifetime between 40 and $120 \mathrm{~mm}$, indicating that $\tau_{\text {eff }}$ grows if more hydrogen is incorporated in the a-Si:H film. However, despite the lowest $\tau_{\text {eff }}$ value at an electrodes' distance of $20 \mathrm{~mm}$, the highest hydrogen concentration is also observed with this electrodes' distance (Fig. 5). The determined hydrogen concentrations

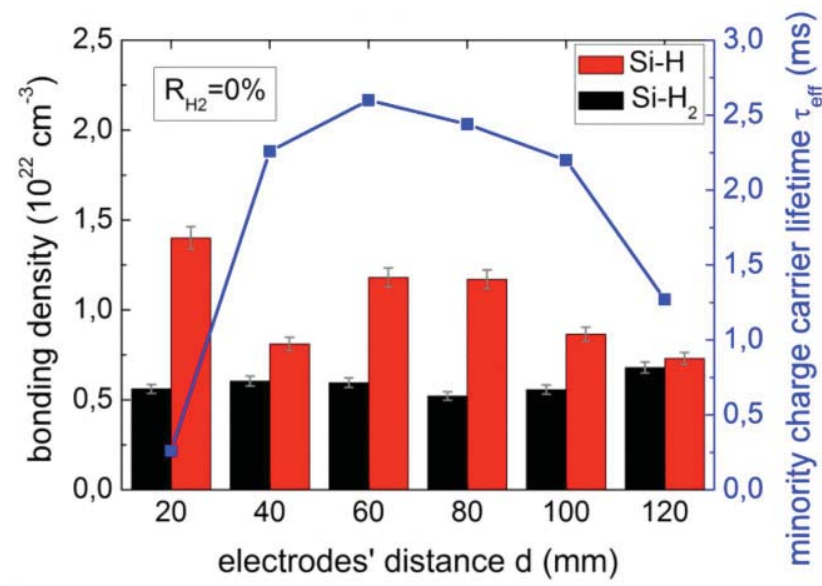

Figure 5 Bonding densities $\left(\mathrm{Si}-\mathrm{H}, \mathrm{Si}-\mathrm{H}_{2}\right)$ and effective minority charge carrier lifetime dependent on electrodes' distance. Lines are guide to the eyes only. of the (i)a-Si:H films are in the same range as reported by other authors [29, 30].

3.4 Optical properties Neither a correlation between refractive index $n$ of the a-Si:H film and electrodes' distance nor between its energy gap $E_{\text {gap }}$ and electrodes' distance is observed (not depicted).

3.5 Discussion According to Kushner [8], the volume between the electrodes in a PECVD operating in parallelplate configuration can be separated into two parts: the sheath regions next to the electrodes, in which power utilization occurs with higher energy processes, and the bulk plasma region, in which power utilization occurs by lower energetic processes (e.g., vibrational excitations). The sheath regions occupy a constant volume independent of electrodes' distance [8]. Therefore, if electrodes' distance decreases, the fraction of power utilization by higher energetic processes increases. As a consequence, more $\mathrm{SiH}_{4}$ is dissociated resulting in an enhanced a-Si:H steady-state growth rate with diminishing electrodes' distance (Fig. 2). The same reasoning applies to the fast grown layer. If more $\mathrm{SiH}_{4}$ is dissociated at the very beginning of the deposition process, fast grown layer thickness rises (Fig. 2).

However, as a result of the constant sheath region volume, the highly energetic particle bombardment intensity on the c-Si wafer surface rises with decreasing electrodes' distance, yielding an enhanced interface defect density and therewith a reduction in minority charge carrier lifetime (Fig. 4). In contrast, larger electrodes' distance results in a higher fraction of power utilization in the plasma bulk due to lower energy processes which is accompanied by less surface bombardment by highly energetic particles.

However, minority charge carrier lifetime drops again with electrodes' distances larger than $60 \mathrm{~mm}$, which can be explained as follows: the average residence time of radicals within the plasma ascends with electrodes' distance [8]. Thus, the probability of secondary chemical reactions after the initial dissociation of silane grows and therewith the density of polyhydrides within the plasma. This rise in polyhydride density is reflected by the grown $\mathrm{Si}-\mathrm{H}_{2}$ bonding density at large electron distance $(120 \mathrm{~mm}$, cf. Fig. 5). The polyhydrides are detrimental to the electronic quality of the a-Si:H film [8] and may therefore account for the decline in minority charge carrier lifetime with increasing electrodes' distance.

4 Doped a-Si:H films In order to generate p-doped a-Si:H films, diborane $\left(\mathrm{B}_{2} \mathrm{H}_{6}\right)$ diluted in hydrogen $(0.5 \%)$ is added to the precursor gases. Hence, in contrast to the intrinsic a-Si:H films, all doped films are deposited at a hydrogen dilution of $R_{\mathrm{H}_{2}}=66 \%$.

The FTIR results of the doped a-Si:H films are therefore not directly comparable to the results of the intrinsic films. Maximal dark conductivity $\sigma_{\text {dark }}$ of the (p)a-Si:H films achieved within this research project is $1.95 \times 10^{-5} \mathrm{~S} \mathrm{~cm}^{-1}$, 
which is in the same order of magnitude as reported by other authors $[14,31]$.

4.1 Electrodes' distance $\sigma_{\text {dark }}$ exhibits a clear dependence on the electrodes' distance, more precisely, $\sigma_{\text {dark }}$ increases with electrodes' distance from $1.14 \times 10^{-8} \mathrm{~S} \mathrm{~cm}^{-1}$ (at $24 \mathrm{~mm}$ ) to $6.61 \times 10^{-6} \mathrm{~S} \mathrm{~cm}^{-1}$ (at $100 \mathrm{~mm}$ ) (Fig. 6).

SIMS measurements reveal an increased total amount of boron incorporated in the a-Si:H films with electrodes' distance from $2.4 \times 10^{20} \mathrm{~cm}^{-3}$ at $40 \mathrm{~mm}$ to $3.7 \times 10^{20} \mathrm{~cm}^{-3}$ at $100 \mathrm{~mm}$. Since the gas flows are kept constant, the distribution coefficient $d_{\mathrm{I}}$ must increase with electrodes' distance (from 0.48 to 0.75 ) as well, meaning that the boron is incorporated slightly more efficient. In order to cause the observed conductivity gain either the amount of boron incorporated electrically active and/or the carrier mobility within the doped film increases considerably with electrodes' distance due to the different plasma conditions (cf. Section 3.5). However, it has not yet been possible to distinguish the contributions of both quantities to $\sigma_{\text {dark }}$ by the measurement techniques available in this project.
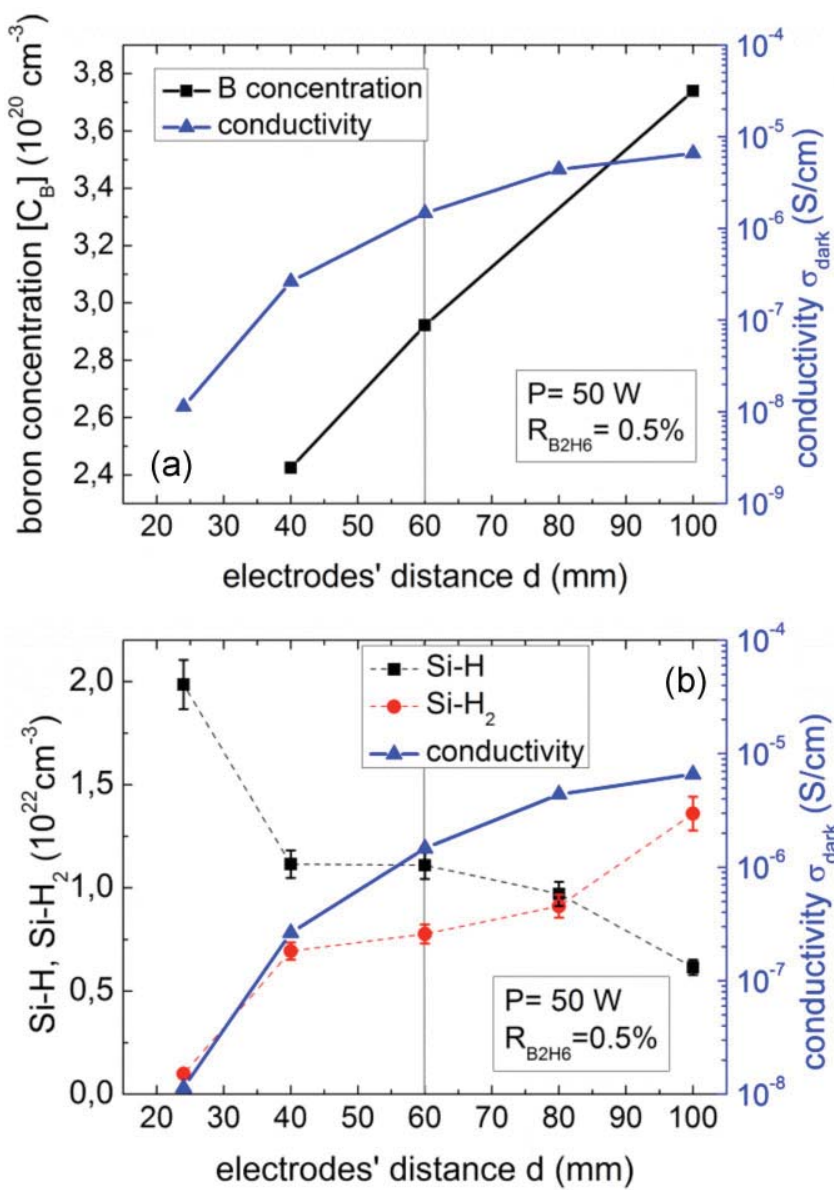

Figure 6 (a) Boron concentration (squares) and dark conductivity (triangles) dependent on electrodes' distance. (b) Silicon-hydrogen bonding density and dark conductivity (triangles) dependent on electrodes' distance. Lines are guide to the eyes only.
As revealed by FTIR measurements and similar to the intrinsic films, $\mathrm{Si}-\mathrm{H}$ bond density increases at the lowest electrodes' distance up to $2 \times 10^{22} \mathrm{~cm}^{-3}$ being twice the amount of the other films. Furthermore, $\mathrm{Si}-\mathrm{H}$ and $\mathrm{Si}-\mathrm{H}_{2}$ bond densities seem to be related to the trend of dark conductivity, that is, $\mathrm{Si}-\mathrm{H}$ bond density diminishes and $\mathrm{Si}-\mathrm{H}_{2}$ bond density rises with ascending $\sigma_{\text {dark }}$. A slight increase of $\mathrm{Si}-\mathrm{H}_{2}$ bond density with $\sigma_{\text {dark }}$ or rather with boron incorporation has been observed by Martín de Nicolás et al. [14], who have investigated (p)a-Si:H films for varying doping gas flows $R_{\mathrm{B}_{2} \mathrm{H}_{6}}$.

Neither the refractive index $n$ nor the optical band gap $E_{\text {gap }}$ of the doped a-Si:H films exhibits any variation with electrodes' distance beyond measurement error.

4.2 Diborane gas flow $\boldsymbol{R}_{\mathrm{B}_{2} \mathrm{H}_{6}}$ Dark conductivity dependent on the diborane gas flow $R_{\mathrm{B}_{2} \mathrm{H}_{6}}$ at a fixed electrodes' distance of $60 \mathrm{~mm}$ is depicted in Fig. 7. As observed by other authors (e.g., [14]), $\sigma_{\text {dark }}$ first rises with diborane flow $R_{\mathrm{B}_{2} \mathrm{H}_{6}}$ but starts dropping at high $R_{\mathrm{B}_{2} \mathrm{H}_{6}}=$ $0.99 \%$ (Fig. 7). The $\sigma_{\text {dark }}$ increase is caused by a higher
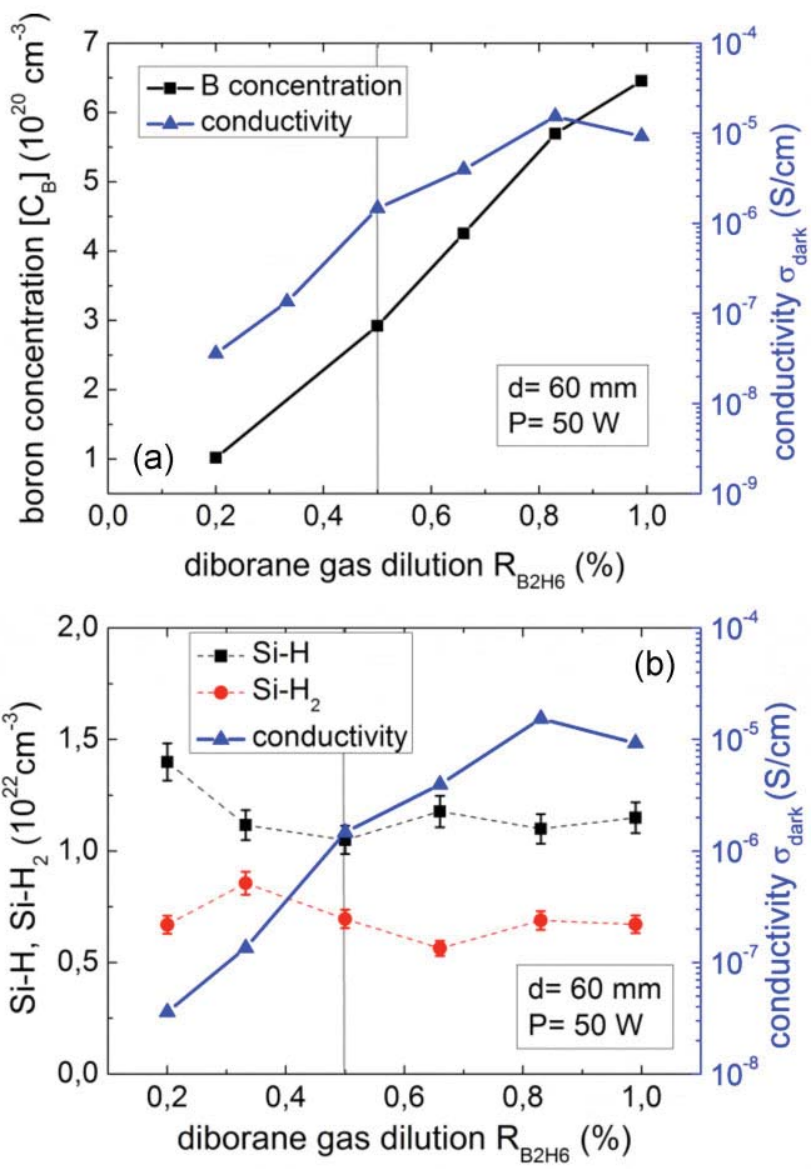

Figure 7 (a) Boron concentration (squares) and dark conductivity (triangles) dependent on diborane gas dilution $R_{\mathrm{B}_{2} \mathrm{H}_{6}}$. (b) Siliconhydrogen bonding density and dark conductivity (triangles) dependent on diborane gas dilution $R_{\mathrm{B}_{2} \mathrm{H}_{6}}$. Lines are guide to the eyes only. 
incorporation of boron in the a-Si:H films (Fig. 7). However, since boron incorporation is accompanied by defect formation [32], this holds good only up to a certain doping threshold where defect density carried into the a-Si:H turns too large. The same development is also reflected in the distribution coefficient, which first rises with $R_{\mathrm{B}_{2} \mathrm{H}_{6}}$ from $d_{\mathrm{I}}=0.51\left(\right.$ at $\left.R_{\mathrm{B}_{2} \mathrm{H}_{6}}=0.2 \%\right)$ to $d_{\mathrm{I}}=0.68\left(\right.$ at $\left.R_{\mathrm{B}_{2} \mathrm{H}_{6}}=0.99 \%\right)$ but diminishes again for $R_{\mathrm{B}_{2} \mathrm{H}_{6}} \geq 0.99 \%\left(d_{\mathrm{I}}=0.65\right)$, although $\left[C_{\mathrm{B}}\right]_{\text {film }}$ still increases (Fig. 7).

Considering the measurement error, both hydrogen-bond densities $\left(\mathrm{Si}-\mathrm{H}, \mathrm{Si}-\mathrm{H}_{2}\right)$ are, in comparison to the variation of the electrodes' distance (Fig. 6) and the deposition power (Fig. 8), nearly not affected by the diborane flow (Fig. 7). Thus, the hydrogen bond densities are not solely affected by the amount of boron incorporated in the a-Si:H film. This contradicts the results of Ref. [14] who have observed an increase of $\mathrm{Si}-\mathrm{H}_{2}$ bond density with $R_{\mathrm{B}_{2} \mathrm{H}_{6}}$. It should be borne in mind that despite changing the diborane concentration of the precursor gas, the silane to hydrogen ratio is held constant $\left(R_{\mathrm{H}_{2}}=66 \%\right)$ during the experiment by adjusting the hydrogen flow.

Furthermore, refractive index and optical band gap do not alter with $R_{\mathrm{B}_{2} \mathrm{H}_{6}}$. Again, this stands in contrast to the
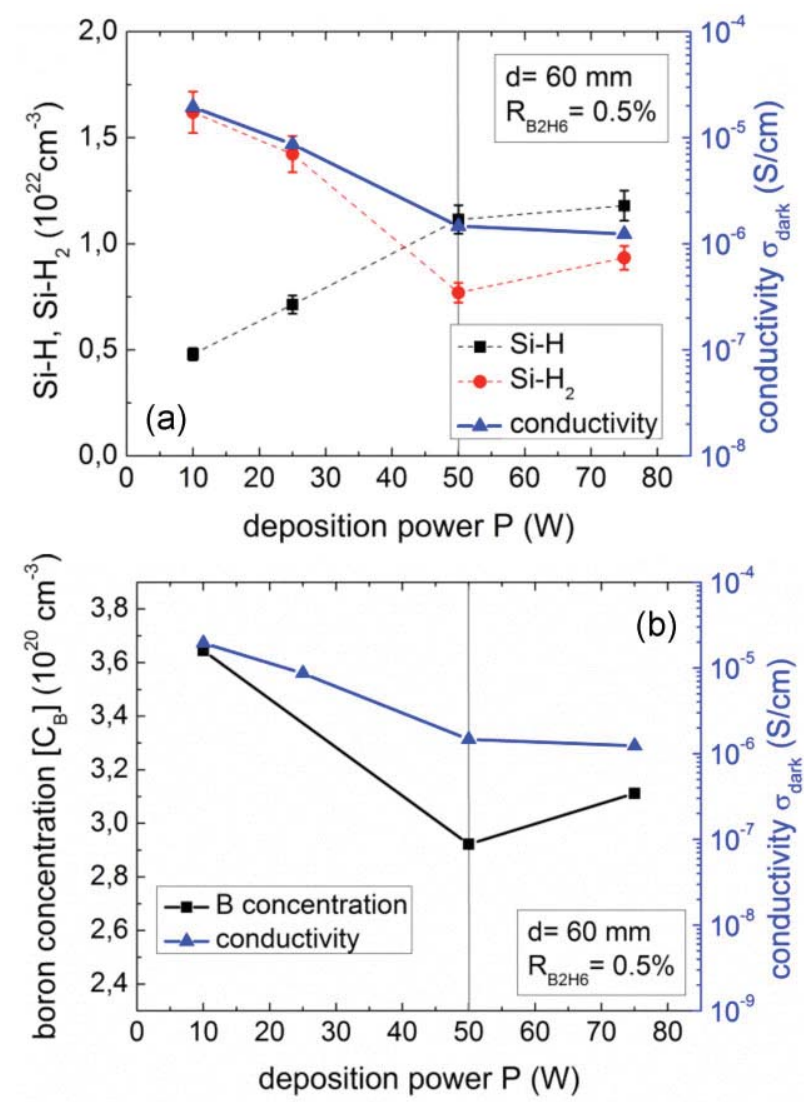

Figure 8 (a) Boron concentration (squares) and dark conductivity (triangles) dependent on deposition power. (b) Silicon-hydrogen bonding density and dark conductivity (triangles) dependent on deposition power. Lines are guide to the eyes only. results of Ref. [14] who have observed an obvious diminishment of $E_{\text {gap }}$ with increasing boron incorporation.

4.3 Deposition power $\boldsymbol{P}$ Decreasing deposition power $P$ at a fixed electrodes' distance of $60 \mathrm{~mm}$ raises the dark conductivity of the (p)a-Si:H films and the amount of boron incorporated into the film (Fig. 8). At the same time, the distribution coefficient raises from 0.62 (at $75 \mathrm{~W}$ ) to 0.73 (at $10 \mathrm{~W}$ ).

Varying deposition power, the silicon-hydrogen bond densities again follow the trend of the dark conductivity as it is the case for a varying electrodes' distance, i.e., $\mathrm{Si}-\mathrm{H}_{2}$ bond density ascends whereas $\mathrm{Si}-\mathrm{H}$ density diminishes with increasing $\sigma_{\text {dark }}$ (Fig. 8).

In this case the increase of boron concentration is accompanied by a broadening of the optical band gap from $1.66 \mathrm{eV}$ for the film deposited at $75 \mathrm{~W}$ to $1.78 \mathrm{eV}$ for the film deposited at $10 \mathrm{~W}$. Refractive index at a wavelength of $600 \mathrm{~nm}$ slightly changes from $4.28(75 \mathrm{~W})$ to $4.02(10 \mathrm{~W})$.

4.4 Discussion As pointed out in Section 3.5, widening the electrodes' distance results in less high energy processes within the plasma bulk [8]. The same can be stated for a reduction of deposition power. In consequence, the trend of the results obtained for the variation of the electrodes' distance is in accordance with the results for deposition power variation, i.e., both $\left[\mathrm{C}_{\mathrm{B}}\right]_{\text {film }}$ and $\sigma_{\text {dark }}$ increase with the fraction of power utilization by less energetic processes. Along with $\sigma_{\text {dark }}$, the structure of the a-Si:H films, i.e., the silicon-hydrogen bonding densities, change. These changes of the bonding densities are not caused by the higher incorporation of boron into the film but rather by the different plasma compositions. Therefore, optical emission spectroscopy (OES) measurements require to be performed in order to obtain a conclusive explanation for the different behavior of the doped a-Si:H films in response to the deposition parameter changes. This may also yield an explanation for the increase of the boron incorporation and therewith of $\sigma_{\text {dark }}$ with widening electrodes' distance and receding deposition power, respectively.

5 Conclusions We have studied the influence of the electrodes' distance upon the electrical, optical, and structural properties of PECV-deposited a-Si:H films to be applied to heterojunction solar cells.

For the intrinsic a-Si:H films, $60 \mathrm{~mm}$ has been found to be the optimal electrodes' distance in terms of high minority charge carrier lifetime and small fast grown layer thickness. By adding hydrogen to the precursor gases, it is even possible to reduce fast grown layer thickness with maintaining the high minority charge carrier lifetime.

This optimal electrodes' distance can be understood as a trade-off between surface damage caused by highly energetic particles from the sheaths region and the amount of polyhydrides within the plasma, which are detrimental to the film quality. Although we have identified a correlation between the total hydrogen amount within the films and 
minority charge carrier lifetime (except for the smallest electrodes' distance), no correlation has been observed between electrodes' distance and the optical properties of the films.

Concerning the boron doped a-Si:H films, dark conductivity ascends with electrodes' distance due to a higher incorporation of boron into the a-Si:H film. The higher boron incorporation as well as the accompanying changes in silicon-hydrogen bonding densities are caused by a higher fraction of power utilization by less energetic processes. OES measurements require to be performed in order to obtain a valid explanation of these experimental observations.

Acknowledgements N. Brinkmann gratefully acknowledges the sponsorship by the scholarship program of the German Federal Environmental Foundation (Deutsche Bundesstiftung Umwelt, DBU). The financial support from the BMU projects FKZ 325179 and FKZ 325168 is gratefully acknowledged in particular for the processing equipment.

\section{References}

[1] S. De Wolf, A. Descoeudres, Z. C. Holman, and C. Ballif, Green 2, 7-24 (2012).

[2] M. Taguchi, A. Yano, S. Tohoda, K. Matsuyama, Y. Nakamura, T. Nishiwaki, K. Fujita, and E. Maruyama, in: Proc. 28th EU PVSEC, Paris, France, 2013, pp. 748-751.

[3] S. Taira, Y. Yoshimine, T. Baba, M. Taguchi, H. Kanno, T. Kinoshita, H. Sakata, E. Maruyama, and M. Tanaka, in: Proc. 22nd EU PVSEC, Milan, Italy, 2007, pp. 932-935.

[4] N. Brinkmann, G. Micard, Y. Schiele, G. Hahn, and B. Terheiden, Phys. Status Solidi RRL 7, 322-325 (2013).

[5] S. Dauwe, J. Schmidt, and R. Hezel, in: Proc. 29th IEEE PVSC, New Orleans, USA, 2002, pp. 1246-1249.

[6] A. Descoeudres, L. Barraud, R. Bartlome, G. Choong, S. De Wolf, F. Zicarelli, and C. Ballif, Appl. Phys. Lett. 97, 1835051-1835053 (2010)

[7] D. Pysch, M. Bivour, K. Zimmermann, C. Schetter, M. Hermle, and S. W. Glunz, in: Proc. 24th EU PVSEC, Hamburg, Germany, 2009, pp. $1580-1585$.

[8] M. J. Kushner, J. Appl. Phys. 63, 2532-2551 (1988).

[9] A. Chowdhury, S. Mukhowadhyay, and S. Ray, Sol. Energy Mater. Sol. Cells 94, 1522-1527 (2010).

[10] P. Kounavis, D. Mataras, N. Spiliopoulos, E. Mytilineou, and D. Rapakoulias, J. Appl. Phys. 75, 1599-1606 (1994).
[11] R. C. Ross and J. Jaklik, J. Appl. Phys. 55, 3785-3794 (1984).

[12] S. Ishihara, M. Kitagawa, T. Hirao, K. Wasa, T. Arita, and K. Mori, J. Appl. Phys. 62, 485-491 (1987).

[13] D. Pysch, C. Meinhardt, M. Hermle, and S. W. Glunz, in: Proc. 25th EU PVSEC, Valencia, Spain, 2010, pp. 18201824.

[14] S. Martín de Nicolás, D. Munoz, A. S. Ozanne, N. Nguyen, and P. J. Riberyon, Energy Procedia 8, 226-231 (2011).

[15] F. A. Bogenschuetz, Ätzpraxis für Halbleiter (Hanser, München, 1967), pp. 67-68.

[16] W. Kern, J. Electrochem. Soc. 137, 1892 (1990).

[17] R. A. Sinton and A. Cuevas, Appl. Phys. Lett. 69, 2510-2512 (1996).

[18] S. Olibet, E. Vallat-Sauvain, and C. Ballif, Phys. Rev. B 76, 035326-1-035326-14 (2007).

[19] A. B. Sproul, J. Appl. Phys. 76, 2851-2854 (1996).

[20] M. Fox, Optical Properties of Solids (Oxford University Press, Oxford, 2010), pp. 44-46.

[21] J. Tauc and A. Menth, J. Non-Cryst. Solids 8, 569-585 (1972).

[22] D. Suwito, Ph.D. thesis, University of Konstanz (2011).

[23] A. A. Langford, M. L. Fleet, and B. P. Nelson, Phys. Rev. B. 45, 13367-13377 (1992).

[24] D. Schroder, Semiconductor Material and Device Characterization (John Wiley and Sons, Hoboken, New Jersey, 2006), pp. 102-103.

[25] R. A. Street, Hydrogenated Amorphous Silicon (Cambridge University Press, Cambridge, 1991), p. 139.

[26] G. Micard, G. Hahn, B. Terheiden, D. Chrastina, G. Isella, T. Moiseev, D. Cavalcoli, A. Cavallini, S. Binetti, M. Acciarri, A. Le Donne, M. Texier, and B. Pichaud, Phys. Status Solidi C 7, 712-715 (2010).

[27] D. Pysch, C. Meinhardt, K.-U. Ritzau, M. Bivour, K. Zimmermann, C. Schetter, M. Hermle, and S. W. Glunz, in: Proc. 35th IEEE Photovoltaic Specialists Conference, Honolulu, Hawaii, 2010, pp. 3570-3576.

[28] R. A. Street, Hydrogenated Amorphous Silicon (Cambridge University Press, Cambridge, 1991), p. 29.

[29] M. Hofmann, Ph.D. thesis, University of Konstanz (2008).

[30] T. F. Schulze, L. Korte, and B. Rech, in: Proc. 26th EU PVSEC, Hamburg, Germany, 2011, pp. 1045-1051.

[31] C. Meinhardt, D. Pysch, M. Bivour, K. Zimmermann, C. Schetter, M. Hermle, and S. W. Glunz, in: Proc. 25th EU PVSEC, Valencia, Spain, 2010, pp. 1810-1815.

[32] R. A. Street, Hydrogenated Amorphous Silicon (Cambridge University Press, Cambridge, 1991), pp. 135-138. 